\title{
Acid exposure and esophageal motility following laparoscopic fundoplication: A comparative randomized study.
}

\author{
Ashraf El Attar, $a$ MD; Hamdy Abdelhady, ${ }^{a} M D$; khaled Zaghloul, $b$ MD; \\ Loai Alahwal, $b$ MD
}

a) Department of Surgery, Tanta University, Tanta, Egypt.

b) Department of Internal Medicine, Tanta University, Tanta, Egypt.

\begin{abstract}
Review: Gastro-esophageal reflux disease is one of the most widely spread diseases allover the world. The principle underlying its surgical management is the creation of a mechanical antireflux barrier between the esophagus and the stomach through the creation of either a total (360 degree), or partial anterior or posterior fundal wraps around the lower esophageal end. The ability of surgery to mechanically control the reflux has been documented. The pathogenesis of gastro-esophageal reflux disease is essentially a motility-related problem with varying contributory elements. The role of different techniques in correcting the underlying motility disorder has been little studied in the randomised literature.
\end{abstract}

Aim: The aim of this study was to compare the ability of the laparoscopic partial posterior and the laparoscopic total fundoplication techniques in objectively controlling the reflux and correcting the underlying esophageal motility disorder in gastro-esophageal reflux patients on the mid-term.

Patients and methods: In the period between June 1998 and July 2007, 40 patients considered for antireflux surgery in the department of surgery, Tanta University Hospital, were prospectively recruited and randomised to undergo either laparoscopic total (Nissen) or laparoscopic partial posterior (Toupet) fundoplication. In addition to the clinical follow-up, objective follow up through esophageal manometry, 24-h pH monitoring and upper gastrointestinal endoscopy were performed 24 months after operation and compared to the same data recorded preoperatively.

Results: Both the total and the partial posterior fundoplication techniques showed excellent control of heartburn and regurgitation postoperatively. This correlated well with the postoperative endoscopic findings, where both techniques were equally effective in correcting hiatus hernias and healing reflux esophagitis. In the Nissen group, the lower esophageal resting pressure significantly increased postoperatively from a median of 23, to $33 \mathrm{mmHg}(p<0.01)$ and the nadir pressure from a median of 0 to $9 \mathrm{mmHg}(p<0.01)$. Similar significant improvements were observed in the Toupet group as well (24 to $31 \mathrm{mmHg}, 2$ to $8 \mathrm{mmHg}$ respectively, $p<0.01$ ), no significant difference was found in-between the studied groups $(P>0.05)$. Length of the abdominal component was significantly increased postoperatively from a median of 3 to $4 \mathrm{~cm}$ and from a median of 2 to $4 \mathrm{~cm}$ in the Nissen and Toupet groups respectively $(p<0.01)$, with no significant difference in-between the studied groups $(P>0.05)$. No significant changes were found in the esophageal body contraction amplitude on comparing the pre and postoperative values in both groups $(p>0.05)$. The median total acid exposure time in the Nissen and Toupet groups was significantly reduced from a preoperative $13 \%$ to $1 \%$ and from $17 \%$ to $0 \%$ respectively, with similar reduction in the number of $\mathrm{pH}$ proven reflux episodes from a median of 24 to 2 and from 30 to 2 respectively $(p<0.01)$. The small number of cases with Barrett's metaplasia in our study made it difficult to draw hard conclusions on the difference between the two surgical techniques in this particular type of patients.

Conclusion: The partial posterior and total fundoplication techniques are equally effective in restoring the lower esophageal pressure profile and in objectively controlling the reflux on the mid-term. No changes in the esophageal body contraction amplitude could be found with either technique. No objective advantages could be demonstrated for either technique to support a tailored approach. 


\section{Review of literature:}

Gastro-esophageal reflux disease (GERD) is one of the most widely spread diseases allover the world, with substantial geographic and racial variation in its prevalence. ${ }^{1}$ The complexity of the natural antireflux armamentarium has led investigators to focus on several potential mechanisms of the disease. Currently, three dominant theories of pathogenesis attribute esophago-gastric junction incompetence to: the transient lower esophageal sphincter relaxations, the hypotensive LES and or anatomical disruption of the esophagogastric junction (EGJ) including, but not limited to, hiatus hernias. ${ }^{2}$

In addition to the above theories, it is known that GERD patients have greater number and greater duration of reflux episodes, and this was taken to reflect a problem with the clearance ability of the esophagus. ${ }^{3}$ Two distinct patterns of acid clearance ability have been described. In patients with prolonged acid reflux times and normal motility, there are repeated superimposed acid reflux episodes giving the appearance of poor acid clearance. While in patients with poor motility, delayed clearance is caused by genuine poor esophageal body clearance. ${ }^{4}$ It was found that twenty five percent of patients with mild esophagitis had peristaltic dysfunction and this rate increased to $48 \%$ in patients with severe esophagitis. ${ }^{5}$ In patients with strictures secondary to GERD, aperistalsis and non-specific motor abnormalities may occur in up to $64 \%$ of patients compared to $32 \%$ of subjects with GERD with no stricture. ${ }^{6}$

Generally speaking, the indications for laparoscopic antireflux surgery are the same as in the open era. The principle underlying the surgical management of GERD is the creation of a mechanical antireflux barrier between the esophagus and the stomach. ${ }^{7}$ This is primarily achieved through the creation of either total (360 degree) or partial anterior or posterior fundal wraps around the lower esophageal end. The ability of the different techniques to mechanically control the reflux has been separately documented. Although it is clear from the above theories that the pathogenesis of GERD is essentially a motilityrelated problem with varying contributory elements, the role of the different techniques in correcting the underlying motility disorder has been little studied in the randomised trials.

\section{Aim:}

The aim of this study was to compare the ability of the laparoscopic partial posterior and the laparoscopic total fundoplication techniques in objectively controlling the reflux and correcting the underlying esophageal motility disorders in GERD patients on the mid-term.

\section{Patients and methods:}

In the period between June 1998 and July 2007, 40 patients with GERD, of those considered for laparoscopic antireflux surgery in the department of surgery, Tanta University Hospital, were prospectively recruited to the study and randomised to undergo either a total (Nissen) or a posterior partial (Toupet) fundoplication using the laparoscopic technique. Twenty patients were recruited in each group. Criteria for exclusion from the study included; previous esophageal or gastric surgery, presence of severe esophageal motility disorder (achalasia), revisional antireflux surgery, patients requiring a concurrent abdominal procedure at the same time (e.g. cholecystectomy), as well as patients with gastric volvulous.

The preoperative work up included history taking through a structured questionnaire, medical examination and investigations focusing on assessing the general fitness for anaesthesia as well as assessment of the possible etiology, extent and complications of GERD. Upper endoscopy (OGD), 24-hour $\mathrm{pH}$ monitoring and esophageal motility studies were performed in all patients. Parameters recorded and compared during $\mathrm{pH}$-monitoring and motility studies are shown in $\operatorname{Table}(\mathbf{1}, \mathbf{2})$. 


\section{Table (1): Compared parameters during pH-monitoring.}

1. Total \% time of $\mathrm{pH}<4$ (normal upper limit $6 \%$ ).

2. Erect $\%$ time of $\mathrm{pH}<4$ (normal upper limit $4 \%$ ).

3. Supine $\%$ time of $\mathrm{pH}<4$ (normal upper limit $2 \%$ ).

4. Total number of reflux episodes (normal upper limit 50), including erect and supine numbers.

5. Symptom index (normal upper limit 50\%).

6. Longest reflux episode (erect/supine) (normal upper limit $10 \mathrm{~min}$ ).

7. Number of reflux episodes $>5$ minutes (normal upper limit <3).

Table (2): Compared parameters during esophageal motility studies.

\begin{tabular}{|l|}
\hline A- LES pressures: \\
- Abdominal component; resting pressure and length. \\
- Respiratory inversion point; position and pressure. \\
- Thoracic component; resting pressure and length. \\
- Actual residual pressure above gastric baseline (nadir LES pressure). \\
\hline B- Esophageal body: \\
- Contractions amplitude.
\end{tabular}

\section{Clinical follow-up:}

Patients were interviewed to follow on their old or new-onset symptoms at 6,12 and 24 months after operation. The same preoperative structured questionnaire was used with stress on the heartburn, regurgitation and postoperative dysphagia. This was used to compare the different techniques and relate to the motility findings.

\section{Objective follow-up:}

Objective investigations through esophageal manometry, 24-h pH monitoring and upper gastrointestinal endoscopy were performed 24 months after operation. Similar parameters as in the preoperative assessments were recorded. Comparison with the preoperative data in the same group as well as in-between the studied groups were undertaken. Patients with Barrett's metaplasia continued under their initial surveillance programs. Only their 24 months data were included in this analysis.

\section{Results:}

In the Nissen group, age ranged form 3857 with a median age of 46 years. Sixty percent were males. In the Toupet group, the median age was 43 with a range of 32-55 years. Males constituted $70 \%$ of this group. Generally, no significant differences in the demographics or operative risks were present in-between the studied groups $\{\mathrm{sex}(\mathrm{p}=0.51)$, age $(\mathrm{p}=0.24)$, BMI $(p=0.97)$ diabetes mellitus $(p=0.64)$, hypertension $(\mathrm{p}=0.68)$, incidence of chest and heart problems $(\mathrm{p}=0.99)$ and history of pervious operations $(\mathrm{p}=0.43)\}$.

\section{Symptomatic follow up}

As shown in Table(3), Significant improvements in heartburn and regurgitation were noted in both groups, with no difference in-between groups during the whole period of follow-up. Table(4) shows the incidence of postoperative dysphagia to solids in both groups. 
Table (3): Heartburn and regurgitation pre and post-operatively.

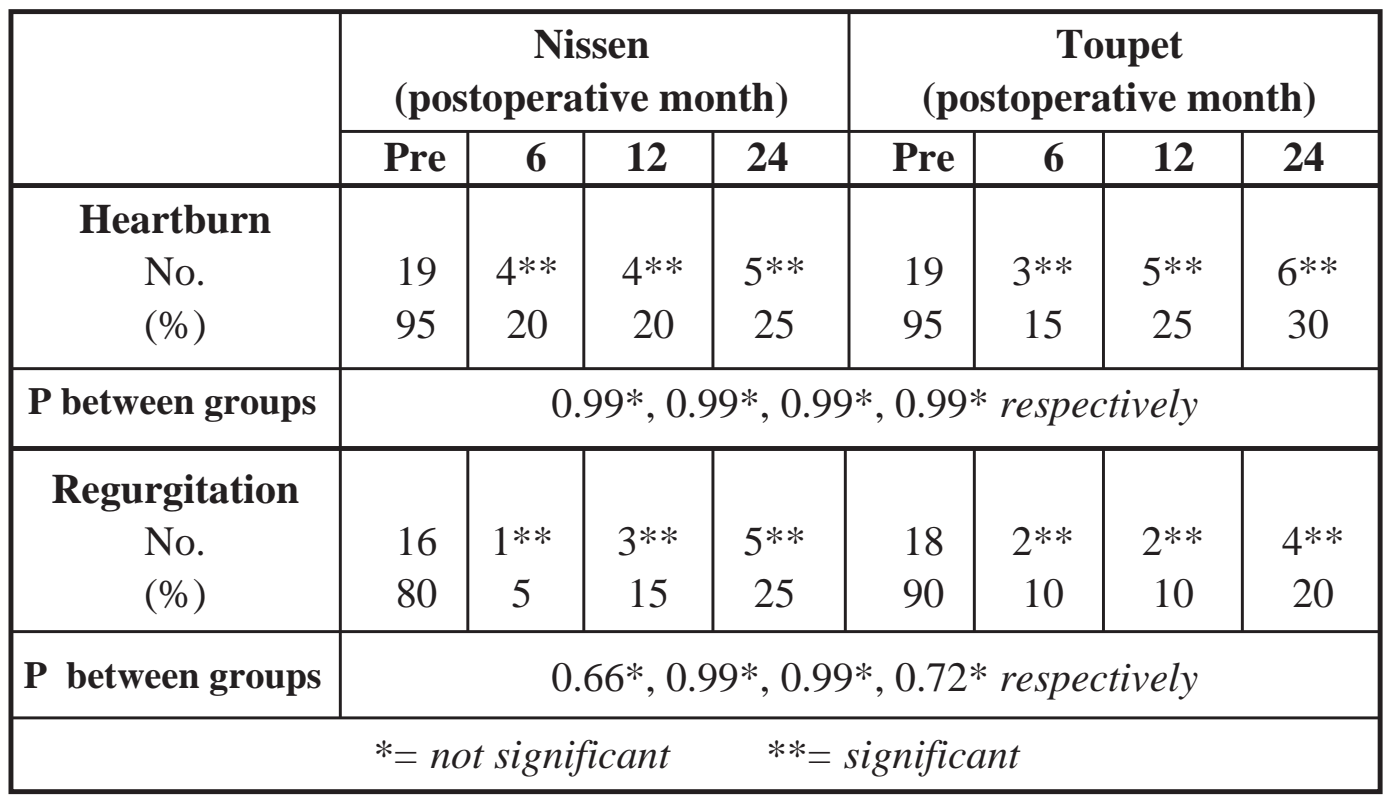

Table (4): Postoperative dysphagia in both groups.

\begin{tabular}{|c|ccc|ccc|}
\hline \multirow{2}{*}{$\begin{array}{c}\text { Dysphagia } \\
\text { (to solids) }\end{array}$} & \multicolumn{3}{|c|}{$\begin{array}{c}\text { Nissen } \\
\text { (postoperative month) }\end{array}$} & \multicolumn{3}{c|}{$\begin{array}{c}\text { Toupet } \\
\text { (postoperative month) }\end{array}$} \\
\cline { 2 - 6 } & $\mathbf{6}$ & $\mathbf{1 2}$ & $\mathbf{2 4}$ & $\mathbf{6}$ & $\mathbf{1 2}$ & $\mathbf{2 4}$ \\
\hline No. & 3 & 1 & 1 & 2 & 1 & 0 \\
$(\%)$ & 15 & 5 & 5 & 10 & 5 & 0 \\
\hline P between groups & \multicolumn{3}{|c|}{$0.14 *, 0.7 * *$ and $0.99 *$ at 6,12 and 24 respectively } \\
\hline & $*=$ not significant & $* *=$ significant \\
\hline
\end{tabular}

\section{Objective follow-up:}

Table(5) sums up the pre and postoperative endoscopic findings in both groups. Two years postoperatively, only one patient $(5 \%)$ in the Nissen group had a small residual hernia, $2 \mathrm{~cm}$ in size above an apparently intact wrap. Also, two patients $(10 \%)$ had residual grade A esophagitis. Of these three patients, only one (with esophagitis) complained of mild heartburn, while the others were asymptomatic. In the other group, no evidence of hiatus hernia recurrence was detected. Only one $(5 \%)$ had residual grade A esophagitis. Clinically, he was asymptomatic. Generally, reflux esophagitis was significantly healed in both groups postoperatively ( $\mathrm{p}=0,02$ and 0.03 in the Nissen and Toupet groups respectively). However, no statistical difference was found in the incidence of hiatus hernias or reflux esophagitis between groups at two years of follow up ( $\mathrm{p}=0.53$ and 0.55 respectively).

The single patient with preoperative stricture complained from early dysphagia postoperatively and received pneumatic dilatation. However, no sign of stricture recurrence was detected postoperatively, despite having mild reflux symptoms.

Although one short segment Barrett's dysplasia showed regression postoperatively from 3 to $1 \mathrm{~cm}$ in the Nissen group, The small number of cases with Barrett's metaplasia made it difficult to compare the outcomes of the different surgical techniques in this particular type of patients, despite excellent control of reflux in all of them by the end of the study. 
Postoperatively, as shown in Table(6), significant improvements in all $\mathrm{pH}$-monitoring parameters were detected in both groups. In the Nissen group, the \% total time of $\mathrm{pH}<4$ was significantly reduced from a preoperative median of $13 \%(2-42)$ to $1 \%(0-8)$ postoperatively $(\mathrm{p}<0.01)$, with a significant reduction in the number of episodes with $\mathrm{pH}$ $<4$ from a median of 24 (2-7) to $2(0-11)$ postoperatively $(\mathrm{p}<0.01)$. Similarly, in the Toupet group, the median \% total time of $\mathrm{pH}$ $<4$ was significantly reduced from $17 \%$ (4$48)$ to $0 \%(0-13)(\mathrm{p}<0.01)$ with a significant reduction in the median number of episodes with $\mathrm{pH}<4$ from 30 (4-101) to $2(0-10)$ postoperatively $(\mathrm{p}<0.01)$. The $\%$ erect and supine times were significantly reduced in both groups as well $(p<0.01)$. No statistical difference was noted on comparing the ambulatory $\mathrm{pH}$ findings in-between groups postoperatively $(p>0.05)$. After 2 years of follow-up, $80 \%$ of patients with residual postoperative heartburn had normal $\mathrm{pH}$ profile. Also, one of the two patients in the Nissen group, in whom abnormal \% total exposure time was detected postoperatively, was totally asymptomatic. The only patient in the Toupet group with abnormal postoperative \% total exposure time complained from mild heartburn.

Table (5): Endoscopic findings pre and 24 months postoperatively.

\begin{tabular}{|c|c|c|c|c|}
\hline & \multicolumn{2}{|c|}{ Nissen } & \multicolumn{2}{|c|}{ Toupet } \\
\hline & Pre & $24 M$ & Pre & $24 \mathrm{M}$ \\
\hline $\begin{array}{l}\text { Hiatus } \\
\text { hernia+ } \\
\text { No. }(\%)\end{array}$ & $\begin{array}{c}12 \\
(60 \%)\end{array}$ & $\begin{array}{c}1 \\
(5 \%)\end{array}$ & $\begin{array}{c}9 \\
(45 \%)\end{array}$ & 0 \\
\hline $\begin{array}{l}\text { Size of hiatus } \\
\text { hernia (cm) } \\
\text { Median (range) }\end{array}$ & $\begin{array}{c}3 \\
(2-5)\end{array}$ & $\begin{array}{c}2 \\
(2)\end{array}$ & $\begin{array}{c}3 \\
(2-4)\end{array}$ & 0 \\
\hline $\begin{array}{l}\text { Esophagitis++ } \\
\text { No. }(\%) \S\end{array}$ & $\begin{array}{c}9 \\
(45 \%)\end{array}$ & $\begin{array}{c}2 \\
(10 \%)\end{array}$ & $\begin{array}{c}7 \\
(35 \%)\end{array}$ & $\begin{array}{c}1 \\
(5 \%)\end{array}$ \\
\hline $\begin{array}{l}\text { Barrett's } \\
\text { No. }(\%)\end{array}$ & $\begin{array}{c}3 \\
(15 \%)\end{array}$ & $\begin{array}{c}3 \\
(15 \%)\end{array}$ & $\begin{array}{c}1 \\
(5 \%)\end{array}$ & $\begin{array}{c}1 \\
(5 \%)\end{array}$ \\
\hline $\begin{array}{l}\text { Length }(\mathrm{cm}) \\
\text { Median (range) }\end{array}$ & $\begin{array}{c}3 \\
(2-4)\end{array}$ & $\begin{array}{c}2 \\
(1-4)\end{array}$ & $\begin{array}{c}2 \\
(2)\end{array}$ & $\begin{array}{l}2 \\
(2)\end{array}$ \\
\hline $\begin{array}{l}\text { Dysplasia } \\
\text { No. }\end{array}$ & 0 & 0 & 0 & 0 \\
\hline $\begin{array}{l}\text { Stricture } \\
\text { No. }(\%)\end{array}$ & $\begin{array}{c}1 \\
(5 \%)\end{array}$ & 0 & 0 & 0 \\
\hline \multicolumn{5}{|c|}{$\begin{array}{l}+P \text { between groups }=0.34 * \text { and } 0.53 * \text { respectively } \\
++P \text { between groups }=0.33 * \text { and } 0.55 * \text { respectively } \\
\S P \text { in the group }=0.02 \text { and } 0.03 \text { respectively } \\
*=\text { not significant } * *=\text { significant, } M=\text { month, No. }=\text { number }\end{array}$} \\
\hline
\end{tabular}


Table (6): Ambulatory pH measurements pre and 24 months postoperatively.

\begin{tabular}{|c|c|c|c|c|}
\hline & \multicolumn{2}{|c|}{ Nissen } & \multicolumn{2}{|c|}{ Toupet } \\
\hline & Pre & $24 \mathrm{~m}$ & Pre & $24 \mathrm{~m}$ \\
\hline $\begin{array}{l}\text { \% Total time } \mathbf{p H}<4 \\
\text { Median (range) }\end{array}$ & $\begin{array}{c}13 \\
(2-42)\end{array}$ & $\begin{array}{c}1 \\
(0-8)\end{array}$ & $\begin{array}{c}17 \\
(4-48)\end{array}$ & $\begin{array}{c}0 \\
(0-13)\end{array}$ \\
\hline P between groups & \multicolumn{4}{|c|}{$0.15^{*}$ and $0.24 *$ respectively } \\
\hline $\begin{array}{l}\text { \% Erect time } \mathbf{p H}<\mathbf{4} \\
\text { Median (range) }\end{array}$ & $\begin{array}{c}7 \\
(1-30)\end{array}$ & $\begin{array}{c}1 \\
(0-7)\end{array}$ & $\begin{array}{c}11 \\
(3-38)\end{array}$ & $\begin{array}{c}0 \\
(0-7)\end{array}$ \\
\hline$P$ between groups & \multicolumn{4}{|c|}{$0.13^{*}$ and $0.17^{*}$ respectively } \\
\hline $\begin{array}{l}\text { \% Supine time } \mathbf{p H}<\mathbf{4} \\
\text { Median (range) }\end{array}$ & $\begin{array}{c}6 \\
(0-24)\end{array}$ & $\begin{array}{c}0 \\
(0-6)\end{array}$ & $\begin{array}{c}5 \\
(1-22)\end{array}$ & $\begin{array}{c}0 \\
(0-6)\end{array}$ \\
\hline$P$ between groups & \multicolumn{4}{|c|}{$0.57^{*}$ and $0.76^{*}$ respectively } \\
\hline $\begin{array}{l}\text { No. of episodes } \mathbf{p H}<\mathbf{4} \\
\text { Median (range) }\end{array}$ & $\begin{array}{c}24 \\
(2-7)\end{array}$ & $\begin{array}{c}2 \\
(0-11)\end{array}$ & $\begin{array}{c}30 \\
(4-101)\end{array}$ & $\begin{array}{c}2 \\
(0-10)\end{array}$ \\
\hline P between groups & \multicolumn{4}{|c|}{$0.76^{*}$ and $0.9 *$ respectively } \\
\hline $\begin{array}{l}\text { Symptom Index } \\
\text { Median (range) }\end{array}$ & $\begin{array}{c}81 \\
(50-100)\end{array}$ & $\begin{array}{c}0 \\
(0-10)\end{array}$ & $\begin{array}{c}82 \\
(47-100)\end{array}$ & $\begin{array}{c}0 \\
(0-35)\end{array}$ \\
\hline$P$ between groups & \multicolumn{4}{|c|}{$0.88^{*}$ and $0.97 *$ respectively } \\
\hline \multicolumn{5}{|c|}{$\begin{array}{l}m=\text { month } \\
*=\text { not significant } \\
\text { No.=number } \\
\text { All parameters significantly improved inside groups } \\
\text { at } 24 \text { months of follow-up } P<0.01\end{array}$} \\
\hline
\end{tabular}

On re-examining the manometric parameters two years postoperatively, a significant improvement in the resting and nadir LES pressures as well as the abdominal component length was observed in both groups. In the Nissen group, the resting LES pressure significantly increased from a preoperative median of 23 (11-65) $\mathrm{mmHg}$, to 33 (16-70) $\mathrm{mmHg}(\mathrm{p}<0.01)$. The nadir LES pressure was also significantly elevated from a median of 0 (0-13) $\mathrm{mmHg}$ to $9(2-16) \mathrm{mmHg}$ postoperatively $(\mathrm{p}<0.01)$. The length of the abdominal component (length of LES below the respiratory inversion point) significantly increased from a median of 3 (1-5) to 4 (3-6) cm postoperatively $(\mathrm{p}<0.01)$. Similar significant improvements in resting and nadir LES pressures as well as in the length of the abdominal component were observed in the Toupet group as well [24 (12-60) to 31(17-62) $\mathrm{mmHg}, 2(0-16)$ to 8 (4-16) $\mathrm{mmHg}$ and 2 (24) to $4(3-6) \mathrm{cm}$ respectively, $\mathrm{p}<0.01$ for all].

No significant changes were found in the esophageal body contraction amplitude on comparing the pre and postoperative measurements in both groups $(p>0.05)$.

Neither the three patients in the Nissen group, nor the two patients in the Toupet group with abnormal nadir pressures postoperatively showed any residual heartburn.

No statistical difference was noted on comparing the manometric findings in-between groups postoperatively ( $p>0.05$ ). The previous data are shown in Table(7). 
Table (7): Manometric measurements pre and 24 months postoperatively.

\begin{tabular}{|c|c|c|c|c|}
\hline & \multicolumn{2}{|c|}{ Nissen } & \multicolumn{2}{|c|}{ Toupet } \\
\hline & Pre & $24 \mathrm{~m}$ & Pre & $24 \mathrm{~m}$ \\
\hline $\begin{array}{l}\text { Resting LES } \\
\text { pressure }(m m H g) \\
\text { Median (range) }\end{array}$ & $\begin{array}{c}23 \\
(11-65)\end{array}$ & $\begin{array}{c}33 \\
(16-70)\end{array}$ & $\begin{array}{c}24 \\
(12-60)\end{array}$ & $\begin{array}{c}31 \\
(17-62)\end{array}$ \\
\hline P between groups & \multicolumn{4}{|c|}{$0.0 .86^{*}$ and $0.65^{*}$ respectively } \\
\hline $\begin{array}{l}\text { Nadir LES } \\
\text { pressure }(\mathrm{mmHg}) \\
\text { Median (range) }\end{array}$ & $\begin{array}{c}0 \\
(0-14)\end{array}$ & $\begin{array}{c}9 \\
(2-16)\end{array}$ & $\begin{array}{c}2 \\
0-16)\end{array}$ & $\begin{array}{c}8 \\
(4-16)\end{array}$ \\
\hline P between groups & \multicolumn{4}{|c|}{$0.93^{*}$ and $0.86^{*}$ respectively } \\
\hline $\begin{array}{l}\text { Abdominal LES } \\
\text { length }(\mathrm{cm}) \\
\text { Median (range) }\end{array}$ & $\begin{array}{c}3 \\
(1-5)\end{array}$ & $\begin{array}{c}4 \\
(3-6)\end{array}$ & $\begin{array}{c}2 \\
(2-4)\end{array}$ & $\begin{array}{c}4 \\
(3-6)\end{array}$ \\
\hline $\mathbf{P}$ between groups & \multicolumn{4}{|c|}{$0.58^{*}$ and $0.76^{*}$ respectively } \\
\hline $\begin{array}{l}\text { Body contraction } \\
\text { amplitude }(\mathrm{mm} H g) \\
\text { Median (range) }\end{array}$ & $\begin{array}{c}62 \\
(26-108)\end{array}$ & $\begin{array}{c}59 \\
(26-106)\end{array}$ & $\begin{array}{c}66 \\
(26-110)\end{array}$ & $\begin{array}{c}65 \\
(30-100)\end{array}$ \\
\hline P between groups & \multicolumn{4}{|c|}{$0.99 *$ and $0.86^{*}$ respectively } \\
\hline \multicolumn{5}{|c|}{$\begin{array}{l}m=\text { month } \\
*=\text { not significant } \\
\text { All parameters significantly improved inside groups at } 24 \text { months } \\
\text { of ollow up } P<0.01 \text { Except contraction amplitude } p=0.21 \text { and } 0.96 \\
\text { in Nissen and Toupet groups respectively. }\end{array}$} \\
\hline
\end{tabular}

\section{Discussion:}

Since Dallemagne et al first described the technique of laparoscopic Nissen fundoplication in 1991, extensive experience with laparoscopic antireflux surgery has been reported. ${ }^{8-11}$ The success of this technique was reflected in the increased number of patients undergoing laparoscopic antireflux surgery compared to the open counterparts. The Center for Disease Control and Prevention in the United States estimated that 12,000 fundoplication were performed by the open route in 1987 compared with 48,000 laparoscopic procedures in $1998 .^{2}$ This success has been linked to an excellent control of the reflux symptoms ${ }^{11}$ and as has been shown in this study, using either the total and partial posterior fundoplication resulted in excellent control of heartburn and regurgitation postoperatively. This correlated well with the postoperative endoscopic findings, where both techniques have been shown to be equally effective in control of hiatus hernias and healing of reflux esophagitis (no statistical difference between groups, $p=0.53$ and 0.55 respectively). Looking separately at both techniques, the reflux esophagitis was significantly healed in both groups at 24 months of follow-up $(78.78 \%$ and $85.72 \%, \mathrm{p}=0,02$ and 0.03 in the Nissen and Toupet groups respectively). This efficacy is reproducible in the literature, whereas $90 \%$ healing rates have been reported with both the laparoscopic Nissen,12,13 and Toupet fundoplication. ${ }^{14}$

DeMeester has proposed precautions to achieve success in antireflux surgery, regardless of the technique used. One such precaution is to restore the basal resting LES pressure to at least twice that of the resting gastric pressure. 15 Hinder et al demonstrated a significant increase in the mean resting LES pressure following laparoscopic Nissen fundoplication in their series of 51 patients. ${ }^{16}$ Also, McAnena and colleagues, in a similar study confirmed this increase in 12 out of 15 patients. ${ }^{17}$ In another study, Pursnani KG et al showed a significant 
increase in the residual LES pressure after laparoscopic Nissen fundoplication. ${ }^{18}$ Judged by DeMeester criteria, we found both techniques to be equally effective in restoring the LES pressure on the mid -term follow up. In the Nissen group, the resting LES pressure significantly increased from a median of 23 , to $33 \mathrm{mmHg}(\mathrm{p}<0.01)$ and the nadir LES pressure from a median of 0 to $9 \mathrm{mmHg}$ postoperatively $(p<0.01)$. Similar significant improvements were observed in the Toupet group as well (24 to $31 \mathrm{mmHg}, 2$ to $8 \mathrm{mmHg}$ respectively, $\mathrm{p}<0,01)$, with no significant differences between the two groups, $\mathrm{P}>0.05$. DeMeester second precaution was to augment the overall length of the sphincter to at least 3 $\mathrm{cm}$. Skinner has also emphasized on the importance of the intra-abdominal length of the high-pressure zone. ${ }^{19}$ Judged again by these criteria, both techniques were found equally effective, as the length of the abdominal component was significantly increased from a median of 3 to $4 \mathrm{~cm}$ and from a median of 2 to $4 \mathrm{~cm}$ postoperatively in the Nissen and Toupet groups respectively $(\mathrm{p}<0.01)$, with no significant differences between the two groups, $\mathrm{P}>0.05$.

The effect of fundoplication on esophageal body function has always been a matter of controversy. In the open era, DeMeester el al suggested that the motility abnormalities seen in patients with GERD improve after surgical correction $^{20}$. Conversely, Johnson and colleagues found no significant improvement in the distal esophageal contraction amplitude after fundoplication. ${ }^{21}$ In the laparoscopic era, Pursanani $\mathrm{KG}$ et al found no significant improvement in the motor function, three months after laparoscopic fundoplication . Our data could not support either technique in this context, as no significant changes were found in the esophageal body contraction amplitude on comparing the pre and postoperative values in both groups ( $\mathrm{p}=0.21$ and 0.96 in the Nissen and Toupet groups respectively). The claimed advantage of the posterior partial fundoplication technique in patients with weak oesophageal body contraction amplitude was not observed in our study. Also, only one, out of seven patients in the Nissen group with preoperative body contraction amplitude below $40 \mathrm{mmHg}$, showed a degree of mild postoperative dysphagia versus none of the six similar cases in the Toupet group. Also, no correlation could be elicited between the preoperative weak body contraction amplitudes and the development of dysphagia at 24 months postoperatively in either group $(\mathrm{p}=0.54)$. Based on the above, our data does not support the notion that partial fundoplication is a better option for GERD patients with week oesophageal body peristalsis or that Nissen fundoplication produces an over tight sphincter. And therefore, does not support the concept of a tailored approach, as proposed by Alexiou and colleagues and supported by others. ${ }^{13-22}$

One of the important findings in this study is the clear ability of both techniques to achieve objective reflux control on the mid-term followup. The median total acid exposure time in the Nissen and Toupet groups was significantly reduced from $13 \%$ to $1 \%$ and from $17 \%$ to $0 \%$ respectively $(\mathrm{p}<0.01)$. There was also a significant reduction in the median number of $\mathrm{pH}$ proven reflux episodes from 24 to 2 and from 30 to 2 in the Nissen and Toupet groups respectively $(\mathrm{p}<0.01)$. Both techniques were equally effective with no statistical differences ( $>>0.05$ ). Generally, we found no proof that the partial posterior is less effective than the total fundoplication in the objective control of reflux. We also found no correlation between the postoperative recurrence of reflux symptoms and the presence of abnormal acid exposure time. These findings are reproducible in the literature, where no objective evidence of recurrent reflux in patients who showed recurrent symptoms or consumed proton pump inhibitors (PPI) postoperatively could be found. It needs to be stressed that the implications of taking these medications in relation to the success of antireflux surgery remains dubious and an explanation might rest in the altered esophageal sensitivity postoperatively. However, this has yet to be proven.

Long-term studies suggest that surgical management of Barrett's esophagus may be preferable to long term acid-suppression therapy . Antireflux surgery aims at correcting the underlying defects often present in patients with Barrett's esophagus including; a deficient lower esophageal sphincter, hiatus hernia, 
abnormal duodeno-gastric reflux and impaired gastric emptying . Thus, successful antireflux surgery should permit objective rather than subjective reflux control, as symptomatic control per se does not mean necessarily the elimination of reflux, reflux injury and Barrett's progression. ${ }^{23}$ Against the isolated reports of poor reflux control in such patients following laparoscopic antireflux surgery, ${ }^{27}$ all Barrett's patients in our study enjoyed an excellent objective control of reflux two years after surgery. Also, the incidence of Barrett's metaplasia did not change postoperatively in both groups. On the contrary, regression from 3 to one $\mathrm{cm}$ was observed in one patient. Although an important finding, it is not yet as groundbreaking as in O'Riordan et al study, where 14 patients (out of 58 Barrett's patients) had complete regression of Barrett's epithelium, with an additional $21 \%$ partial regression following laparoscopic antireflux surgery . However, the small number of cases with Barrett's metaplasia in our study made it difficult to draw hard conclusions on the different effect of the two surgical techniques in this particular type of patients.

\section{Conclusion:}

The partial posterior and the total fundoplication techniques are equally effective in restoring the LES pressure profile and in objectively controlling the reflux on the midterm follow-up. No change in the esophageal body contraction amplitude could be found with either technique. No objective advantages could be demonstrated for either technique to support a tailored approach. Our data also confirmed the ability of the laparoscopic antireflux surgery to achieve excellent reflux control and even regression in Barrett's metaplasia patients; however, further studies are needed in this respect.

\section{References:}

1- Sonnenberg A, El Serag HB: Clinical epidemiology and natural history of gastroesophageal reflux disease. Yale $J$ Biol Med 1999; 72: 81-92.

2- Orlando RC: Pathophysiology of gastroeophageal reflux disease: Esophageal epithelial resistance. In: The esophagus.
Castell DO, Richter JE (Editors); Philadelelphia: Lippincott Williams \& Wilkins (Publishers); 1999; p.409-420. 3- DeMeester TR, Wang CI, Wernly JA, et al: Technique, indications, and clinical use of 24-hour esophageal $\mathrm{pH}$ monitoring. $J$ Thorac Cardiovasc Surg 1980; 79: 656.

4- Barham CP, Gotley DC, Mills A, et al: Oesophageal acid clearance in patients with severe oesophagitis. Br J Surg 1995; 82: 333-337.

5- Kahrilas PJ, Dodds WJ, HoganWJ, et al: Esophageal peristaltic dysfunction in peptic esophagitis. Gastroenterology 1986; 91: 897-904.

6- Ahtaridis G, SnapeWJ, Cohen S: Clinical and manometric findings in benign peptic strictures of the esophagus. Dig Dis Sci 1979; 24: 858-861.

7- Lundell L, Abrahamsson H, Ruth M, et al: Long-term results of a prospective randomized comparison of total fundic wrap (Nissen-Rossetti) or semifundoplication (Toupet) for gastrooesophageal reflux. Br J Surg 1996; 83: 830-835.

8- Weerts JM, Dallemagne B, Hamoir E, et al: Laparoscopic Nissen fundoplication: detailed analysis of 132 patients. Surgical Laparoscopy and Endoscopy 1993; 3: 359364.

9- Cuschieri A, Hunter J, Wolfe B, et al: Multicenter prospective evaluation of laparoscopic antireflux surgery: Preliminary report. Surgical Endoscopy 1993; 7: 505510.

10-Hunter JG, Trus TL, Branum GD, et al: A physiologic approach to laparoscopic fundoplication for gastroesophageal reflux disease. Ann Surg 1996; 223: 673-685.

11-Hunter JG, Champion JK: Laparoscopic Nissen fundoplication. In: Endosurgery. J Hunter (Editor); Springer-Verlag (Publisher); 2001; 32: p.305-313.

12-Parshad R, Kumar MV, Bal S, et al. Laparoscopic Nissen fundoplication; results of a prospective pilot study. Tropical Gastroenterology 2003; 24(3): 152-156.

13-Alexiou C, Beggs D, Salama FD, et al: A tailored surgical approach for gastrooesophageal reflux disease: The 
Nottingham experience. European Journal of Cardio-Thoracic Surgery 2000; 17(4): 389-395.

14-Kabbej M, Cargill G, Fekete F: Gastroesophageal reflux treated by posterior hemifundoplication: 251 cases. Presse Medicale 1992; 21(29): 1369-1373.

15-DeMeester TR, Bonavina L, Albertucci M: Nissen fundoplication for gastroesophageal reflux disease: Evaluation of primary repair in 100 consecutive patients. Ann Surg 1986; 204: 209.

16-Hinder RA, Filipi CJ, Wetscher G, et al: Laparoscopic Nissen fundoplication is an effective treatment for gastroesophageal reflux disease. Annals of Surgery 1994; 220(4): 472-481.

17-McAnena OJ, Willson PD, Evans DF, et al: Physiological and symptomatic outcome after laparoscopic gastric fundoplication. British Journal of Surgery 1995; 82(6): 795-797.

18-Pursnani KG, Sataloff DM, Zayas F, et al: Evaluation of the antireflux mechanism following laparoscopic fundoplication. British Journal of Surgery 1997; 84(8): 1157-1161.

19-Skinner DB: Pathophysiology of gastrointestinal reflux. Ann Surg 1985; 202: 546-556.

20-DeMeester TR, Johnson LF, Kent AH: Evaluation of current operations for the prevention of gastroesophageal reflux. Ann Surg 1974; 180: 511-525.
21-Johnson DA, Winters C, Spurling TJ: Esophageal acid sensitivity in Barrett's esophagus. J Clin Gastroenterol 1987; 9: 23-27.

22-Cheng-Xiang Shan, Wei Zhang, XiangMin Zheng, et al: Evidence-based appraisal in laparoscopic Nissen and Toupet fundoplications for gastroesophageal reflux disease. World J Gastroenterol 2010; 16(24): 3063-3071.

23-Stewart GD, Watson AJM, Lamb PJ, et al: Comparision of three different procedures for antireflux surgery. British Journal of surgery 2004; 91: 724-729.

24-Lord RVN, Kaminski A, Oberg S, et al: Absence of gastroesophageal reflux disease in a majority of patients taking acid suppression medications after Nissen fundoplication. J Gastrointest Surg 2002; 6: 3-10.

25-O'Riordan JM, Byrne PJ, Ravi N, et al: Long-term clinical and pathologic response of Barrett's esophagus after antireflux surgery. The American Journal of Surgery 2004; 188: 27-33.

26-Viljakka M, Saali K, Koskinen M: Antireflux surgery enhances gastric emptying. Arch Surg 1999; 134: 18-21.

27-Csendes A, Burdiles P, Braghetto I, et al: Dysplasia and adenocarcinoma after classic anti-reflux surgery in patients with Barrett's esophagus. Ann Surg 2002; 235: 178-185. 